\author{
Aneta Pawlak \\ Uniwersytet Mikołaja Kopernika (Toruń) \\ anetapawlak@umk.pl
}

\title{
El uso de la coma en las estructuras explicativas y especificativas: un estudio contrastivo español-polaco
}

\begin{abstract}
:
The Use of the Comma with the Incidental Clauses: a Contrastive Study Spanish-Polish

The objective of the article is to present the use of the comma with the incidental clauses which in Spanish are distinguished by their function in explicativas and especificativas. Considering syntactic constructions such as nominal appositions or adjectival subordinate clauses, the basic rules of punctuation established for these structures in both languages have been set out. Besides of the analogues uses ofthe comma, the oppositeor different uses of the comma have been also distinguished and they can be a source of incorrect spelling, due to the negative interference by the Polish language. Keywords: spelling, punctuation marks, basic rules of punctuation, syntax, incidental clauses
\end{abstract}




\section{Streszczenie:}

Użycie przecinka $\mathrm{z}$ wyrażeniami wtrąconymi: studium porównawcze języka hiszpańskiego $\mathrm{z}$ językiem polskim

Celem artykułu jest przeprowadzenie studium komparatywnego zasad użycia przecinka w wyrażeniach wtrąconych, które w języku hiszpańskim rozróżniane są według pełnionej funkcji na explicativas i especificativas. Biorąc pod uwagę konstrukcje składniowe, takie jak przydawki czy zdania podrzędnie złożone przydawkowe, zostają przedstawione podstawowe zasady interpunkcji ustalone dla tych struktur w obu językach. Oprócz podobieństw wyróżnia się także różnice w interpunkcji, które mogą być źródłem błędów ortograficznych dla osób uczących się języka hiszpańskiego.

Slowa kluczowe: ortografia, znaki interpunkcyjne, zasady interpunkcji, składnia, wyrażenia wtrącone

Abordando el tema de la coma como signo lingüístico, entramos en el territorio de la ortografía que, como resaltan la RAE y la ASALE [2010: XL], "representa el pilar fundamental de la unidad de la lengua" ${ }^{1}$. De hecho, la finalidad de la ortografía es estudiar la manera correcta de escribir, por lo cual se ocupa de numerosas materias tales como la representación gráfica de los fonemas, de las unidades léxicas y del acento; la escritura de los nombres propios, de las expresiones numéricas y de las expresiones procedentes de otras lenguas; el uso de los signos ortográficos y de las letras mayúsculas y minúsculas.

Por lo que se refiere a los signos ortográficos, es preciso mencionar que son marcas gráficas que sirven para la correcta lectura e interpretación de los textos escritos. Según las aportaciones de la RAE y la ASALE [2010: 278], los signos ortográficos, de acuerdo con sus principales funciones, se subdividenen tres grupos, eso es,

1 Cabe subrayar que la RAE y la ASALE [2010] conceden precisamente a la ortografía el papel unificador del español, dado que la fonología, la morfología, la sintaxis y el léxico están sujetos a los parámetros de variación geográfica, social, cultural y situacional. En el plano ortográfico, en cambio, una misma representación gráfica hace que se desvanezcan todas las diferencias entre las variantes del español. 
en signos diacríticos, en signos de puntuación y en signos auxiliares. Entre los signos diacríticos se hallan la tilde y la diéresis, que cumplen una función distintiva. Los signos auxiliares, en cambio, tienen muy variadas funciones sobre todo de carácter periférico y abarcan tales marcas gráficas como el guión, la barra, la llave, el apóstrofo, la antilambda, el asterisco, el signo de párrafo, el calderón y la flecha. A su vez, entre los signos de puntuación se distinguen el punto, la coma, el punto y coma, los dos puntos, los paréntesis, los corchetes, la raya, las comillas, los puntos suspensivos y los signos de interrogación y exclamación. Su función principal esdelimitarlasunidades que componen el discurso, poniendo de manifiesto las relaciones sintácticas y lógicas entre ellas para facilitar su comprensión y la correcta interpretación, evitando así posibles ambigüedades. Además, informan sobre el carácter especial de determinados constituyentes del discurso y hacen destacar, p.ej., citas, incisos, intervenciones de distintos interlocutores en un diálogo, etc.

Después de esta breve introducción referente a la ortografía, vamos a enfocar nuestra atención en la coma, uno de los signos de puntuación que tanto en español como en polaco puede plantear dudas a la hora de escribirlo. Por suerte, de gran ayuda resultan ser las normas básicas de puntuación establecidas precisamente a propósito de aportar indicaciones, a veces también sugerencias, que pretenden disipar las incertitumbres de quien escribe. Aún así, no se debe perder de vista el hecho de que las normas básicas de puntuación varían de una lengua a otra, puesto que no son universales y se someten a los criterios propios de cada idioma. De ahí que aparezca la idea de realizar el presente estudio contrastivo del uso de la coma en español y en polaco. No obstante, ante un tema tan vasto y complejo, optamos por restringir la envergadura del análisis a las estructuras explicativas y especificativas. Tomando el español como lengua de referencia, vamos a efectuar un estudio comparativo español-polaco de las normas básicas de puntuación establecidas para las susodichas construcciones.

Asimismo, hemos de señalar que el presente trabajo está dedicado principalmente para los polacos que estudian español como segunda 
lengua, puesto que en las páginas que siguen, en la mayoría de los casos, se prescinde de las traducciones de las oraciones polacas.

Además, cabe avisar que las reglas de puntuación del español vienen de la Ortografía de la lengua española, una obra magistral de la Real Academia Española y la Asociación de Academias de la Lengua Española del año 2010.

En lo que concierne a las normas básicas de puntuación del polaco, recurrimos a los estudios de Bańko [2006], de Wielki stownik ortograficzny (2006) y de Markowski y Wichrowska [2009].

No obstante, antes de comenzar el análisis contrastivo propiamente dicho, recordemos que la coma es un signo de puntuación que sirve para establecer los límites entre las unidades lingüísticas que constituyen el enunciado. Desde el punto de vista funcional, la coma desempeña la función demarcativa ${ }^{2}$, siendo así obligatoria su presencia en un enunciado. La función demarcativa sale a la luz, p.ej., en las enumeraciones y en la yuxtaposición ${ }^{3}$. El primer término, la enumeración, se refiere a una expresión sucesiva y ordenada de las partes de un todo. La yuxtaposición, en cambio, es una coordinación de dos a más elementos sintácticos sin nexo alguno. Tanto en español como en polaco la presencia de la coma es obligatoria para separar entre sí las unidades lingüísticas que constituyen enumeraciones (Juan es alegre, simpático, trabajoso; Jan jest wesoly, sympatyczny, pracowity) y oraciones yuxtapuestas (Por las tardes fregaba los platos, sacaba la basura, hacia la compra; Po południu zmywała naczynia, wyrzucata śmieci, robila zakupy).

Cabe asimismo mencionar que hay ciertos casos en que la presencia de la coma en el enunciado no es obligatoria, sino que depende de la preferencia de quien escribe. En tal caso, su aparición es completa-

${ }^{2}$ Como apuntan la RAE y la ASALE [2010: 283], la coma es un delimitador principal junto con el punto, el punto y coma y dos puntos. Mientras tanto, la raya, el paréntesis, los corchetes y las comillas delimitan sólo fragmentos de texto.

3 En la lengua polaco, según aclara. Bańko [2006: 486], se habla en tal caso de zdania wspótrzędne połaczone bezspójnikowo. 
mente opcional y no afecta en absoluto a las características sintácticosemánticas del enunciado. Conforme con la RAE y la ASALE [2010: 304], la escritura de coma implica, entonces, "diferencias que afectan al enfoque que se da al mensaje, a los matices expresivos que quieren transmitirse o, simplemente, a la claridad del texto". Por tanto, es de suma importancia fijarse ahora más de cerca en los enunciados que permiten tal uso facultativo de la coma, que, recordemos, no equivale a la total espontaneidad de quien escribe, sino que está limitado a determinados lugares del enunciado, lo que ponen de manifiesto las siguientes oraciones:

Si llueve, a veces salimos a buscar setas, frente a Si llueve, a veces, salimos a buscar setas.

Íbamos a ir juntos al cine, pero al final no nos pusimos de acuerdo, frente a Íbamos a ir juntos al cine, pero, al final, no nos pusimos de acuerdo.

A las ocho de la mañana hago deporte, frente a A las ocho de la mañana, hago deporte.

A finales del siglo XIX, en América se produjo un fuerte desarrollo de los núcleos urbanos, frente a $A$ finales del siglo XIX, en América, se produjo un fuerte desarrollo de los núcleos urbanos.

A la vista de los ejemplos expuestos, cabe comentar que aunque la presencia facultativa de la coma prácticamente no aporta ningún cambio interpretativo, puede, en cambio, ejercer cierta influencia en la lectura más enfática de las unidades marcadas entre comas que, en nuestro caso, son a veces, al final, a las ocho de la mañana y en América. Con ello, saltan a la vista las funciones prosódicas que también puede desempeñar la coma al indicar una pausa breve en la cadena hablada.

Ahora bien, con respecto a la lengua polaca, el uso facultativo de la coma se da, p.ej., con los incisos que describen circunstancias que acompañan a la acción verbal. Siguiendo a Wielki słownik ortograficzny [2006], compárense, al respecto, las dos siguientes oraciones: 
Powiedziała, że ma nas dość i obróciwszy się na pięcie, wyszła, frente a Powiedziała, że ma nas dość $i$, obróciwszy się na pięcie, wyszła.

En la primera oración, $i$ obróciwszy się na pięcie, sin una coma antepuesta,se informa sobre una circunstancia que acompaña a la acción de salir. Mientras tanto, en la segunda versión, obróciwszy się na pięcie, estamos ante un inciso.

El inciso, que en polaco podría ser parafraseado como wyrażenie wprowadzajace wyjaśnienia, es cualquier estructura gramatical suplementaria que aporta tales informaciones incidentales como precisiones, ampliaciones, rectificaciones o circunstancias a lo dicho. Son elementos periféricos respecto al enunciado en el que aparecen, tienen cierta autonomía gramatical y semántica, por lo que se emplea la coma para encerrarlos. Además, en la cadena hablada estas estructuras gramaticales suplementarias están marcadas por un perfil melódico peculiar. Como precisan la RAE y la ASALE [2010: 306], esta información incidental, llamada inciso, "suele constituir una unidad tonal independiente del resto del enunciado, del que aparece separada por una breve pausa o bien por una inflexión, y se pronuncia en un registro diferente al de la oración principal".

A sabiendas que, por regla general, los incisos se aíslan mediante comas del resto del enunciado, lo notable es también mencionar que pueden aparecer en posición medial en el enunciado y, entonces, se escriben entre dos comas, p.ej., Estos medicamentos, como se ha explicado, son muy eficaces. En cambio, cuando ocupan la posición inicial o final, se separan por una coma del resto del enunciado, p.ej., Como se ha explicado, estos medicamentos son muy eficaces y Estos medicamentos son muy eficaces, como se ha explicado.

En resumidas cuentas, la coma, además de organizar sintácticamente los elementos lingüísticos dentro de un enunciado, sirve también para marcar pausas breves o débiles en la cadena hablada. Aunque no es nuestro propósito ahondar en las coincidencias y divergencias de los criterios sintácticos y prosódicos a la hora de escribir coma en un enunciado, no obstante, consideramos notorio mencionar al respecto la siguiente observación de la RAE y la ASALE [2010: 313]: 
Como regla general, la puntuación no debe romper la dependencia que se establece entre los grupos sintácticos más fuertemente vinculados desde el punto de vista sintáctico y semántico, con independencia de que, en la pronunciación, esos grupos se separen del resto del enunciado mediante una pausa o una inflexión tonal.Ahora bien, entre las estructuras explicativas y especificativas que tomamos en consideración en el presente estudio, se hallan tales construcciones gramaticales como aposiciones nominales, apodos o sobrenombres, adjetivos o grupos adjetivales y oraciones adjetivas o de relativo. Por línea general, las estructuras explicativas, que tanto en español como en polaco se separan mediante comas del resto del enunciado, se caracterizan por interrumpir el curso del enunciado, agregando alguna precisión o comentario sobre el elemento nominal que las precede. Las estructuras especificativas, en cambio, no se separan mediante comas del resto del enunciado, debido a que constituyen una parte integral del mensaje y se integran en el grupo nominal que las precede, restringiendo o delimitando su significado.

En lo que atañe a las aposiciones, son sustantivos o grupos nominales que sirven para aclarar o ampliar la información sobre otro nombre o sintagma nominal que los preceden, adquiriendo así un carácter explicativo. Siempre escribimos comas para separar las aposiciones nominales en función explicativa del resto del enunciado, como lo ilustran los siguientes ejemplos [RAE y la ASALE, 2010: 308]:

La presentación de Eduardo Romero, el comisario de la exposición, fue muy aplaudida.

Mi hermano, Arturo, estuvo allí.

En cambio, nunca separamos mediante comas las aposiciones nominales en función especificativa, por lo que en la oración Mi hermano Arturo estuvo allí la ausencia de las comasimpone la interpretación de que la persona que habla identifica a uno de sus hermanos. Al contrario, en la misma oración anteriormente mencionada, pero con la aposición explicativa aislada mediante comas, se deduce que la persona que habla solo tiene un hermano que se llama Arturo. 
En polaco asimismo las aposiciones explicativas (przydawki apozycyjne) se aíslan mediante comas del resto del enunciado [Markowski, Wichrowska, 2009: LXII y LXIII]:

Jan Kowalski, dyrektor zakladu, jest optymista.

W naszym mieszkaniu, w sypialni, zagnieździly się myszki.

Un comentario aparte merecen los nombres y los apellidos en posición pospuesta al sustantivo o grupo nominal. Detengámonos, pues, para analizar las siguientes oraciones, aludidas por Markowski y Wichrowska [2009: LXIII]:

Ostatni król Polski, Stanistaw August Poniatowski zmart w Petersburgu.

Ostatni król Polski Stanisław August Poniatowski zmart w Petersburgu.

Como se puede notar, en tales construcciones se da la posibilidad de escribir coma optativamente, pero sólo en el lugar antepuesto a los nombres propios en función de aposición. Además, otra característica relevante es que nunca se escribe coma detrás de dicha aposición, como lo ilustran claramente las dos oraciones mencionadas.

Los sobrenombres o apodos asimismo pueden interpretarse como aposiciones explicativas cuando pueden sustituir al nombre verdadero [RAE y ASALE, 2010: 309]:

José Martínez Ruiz, Azorín, perteneció a la generación del 98.

No obstante, si los sobrenombres forman parte del nombre propio, no pueden separarse de él mediante comas, como es el caso de Alfonso II el Casto.

Para el idioma polaco se pueden citar unos ejemplos análogos a los supra mencionados.

Así pues, no ponemos coma cuando el sobrenombre se integra al nombre propio, p.ej., Kazimierz III Wielki. Al contrario, aislamos mediante comas los apodos que funcionan como aposiciones explicativas: Cyrus II Wielki, zwany także Starszym, byt królem Persji z dynastii Achemenidów.

En lo referente a los incisos representados por los adjetivos o grupos adjetivales en función explicativa, estos se separan por comas 
del resto del enunciado y siempre están pospuestos al sustantivo, añadiendo una característica más del antecedente, sin modificar su extensión significativa, por lo que su omisión no impediría la comprensión del mensaje. P.ej., en la oración Los soldados, cansados, volvieron al campamento con dos horas de retraso, conforme con la RAE y la ASALE [2010: 308], con el adjetivo en función explicativa cansados, se explica que todos los soldados estaban cansados $\mathrm{y}$, por eso, se retrasaron.

Al contrario, si los adjetivos desempeñan la función especificativa, no se escriben entre comas, puesto que añaden una característica que modifica la extensión significativa del antecedente y son indispensables para la interpretación del mensaje. Así pues, en la misma oración, pero privada de comas Los soldados cansados volvieron al campamento con dos horas de retraso, se especifica que, del total de los soldados, solamente aquellos que estaban cansados, llegaron con retraso.

Respecto a las normas básicas de puntuación de la lengua polaca, por un lado, tampoco se escribe coma entre los adjetivos o grupos adjetivales en función especificativa (przydawki nierównorzędne) que además, por regla general, se anteponen al sustantivo al que complementan. Siguiendo a M. Bańko [2006: 492], fíjense en las siguientes oraciones que ilustran dicha norma:

Pierwszy powojenny film polski dotyczyt kwestii okupacyjnych (lo que quiere decir pierwszy z powojennych filmów).

Wspótczesna polska literatura ma wiele tlumaczeń na języki obce (lo que quiere decir wspótczesna czesść polskiej literatury).

Por otro lado, también se escribe coma para aislar los adjetivos y grupos adjetivales en función explicativa (przydawki równorzędne) [Markowski, Wichrowska, 2009: LXII]: Młoda, ładna, bardzo miła dziewczyna.

Pasemos finalmente a las oraciones subordinadas adjetivas o de relativo. Cuando ejercen la función explicativa, se separan mediante comas del resto del enunciado, siendo introducidas bien por la conjunción que (La casa, que está al borde del mar, es muy luminosa), o bien por una preposición más la conjunción que (Don Alfonso, 
a quien todos recordamos con cariño, estuvo siempre a nuestro lado). Al ser incisos, recordemos que pueden omitirse sin hacer incomprensible el mensaje y al leerlas se pronuncian entre pausas con un tono de voz más bajo.

Al contrario, si la oración tiene función especificativa, o sea, restringe o delimita la extensión significativa o referencial del sustantivo-antecedente, entonces en la lectura forma un solo grupo fónico con el sustantivo sin pausa ni comas en la escritura: La casa que está al borde del mar es muy luminosa. En esta oración seespecifica que, de entre todas las casas que hay en una zona determinada, se habla de la que está situada al borde del mar. Mientras que en la oración adjetiva explicativa supra mencionada, se explica que la casa de la que se habla está al borde del mar.

Ahora bien, por lo referente a la lengua polaca, según aportan Markowski y Wichrowska [2009: LX], las oraciones subordinadas adjetivas intercaladas en función de incisos (zdania podrzędnie złożone przydawkowe) siempre se aíslan por comas del resto del enunciado: Ludzie, którzy gromadzili się wokót ratusza, byli coraz bardziej agresywni. De hecho, a diferencia de la lengua española, en polaco no hay posibilidad de prescindir de las comas, dado que este tipo de oraciones no hace distinción entre la función explicativa y especificativa, por lo cual pueden generarse interferencias negativas de la lengua polaca.

Por consiguiente, repárnse ahora en que en El hombre del que te hablé ayer es mi tío no se admiten comas *El hombre, del que te hablé ayer es mi tío. Pero sí en Este hombre, del que te hablé ayer, es mi tío, por lo que es incorrecta la ausencia de las comas *Este hombre del que te hablé ayer es mi tío. Mientras tanto, en polaco las respectivas traducciones de las susodichas oraciones son las siguientes: Mężczyzna, o którym ci wczoraj mówilem, jest moim wujkiem y Ten mężczyzna, o którym ci wczoraj mówitem, jest moim wujkiem. Sin embargo, no se puede dar por zanjada esta parte del análisis contrastivo sin mencionar las contrucciones polacas con formas no verbales terminadas en -ąc, -wszy, -łszy, llamadas imiestowowe równoważiki zdania. Conforme con Bańko [2006: 492], cuando funcionan como 
atributo (przydawka) que acompaña al sustantivo para especificarlo, no se aíslan mediante comas del resto del enunciado, como lo reflejan las siguientes dos oraciones:

Podróżni jadący tym pociagiem sa obowiązani mieć miejscówki (lo que quiere decir que ci z podróżnych, którzy jada tym pociagiem).

Robotnikom zatrudnionym przy budowie mostu zapewniono bezpieczne warunki pracy (loquequieredecirque tym spośród robotników, którzy zostali zatrudnieni przy budowie mostu). Como se hace notar a la vista de las estructuras gramaticales en cuestión, mientras que la lengua polaca dispone de dos construcciones sintácticamente diferentes, el español se vale de una misma estructura oracional para expresar el carácter explicativo y especificativo de la información aportada.

No obstante, y a modo de conclusión, aunque las estructuras sintácticas tomadas en consideración en el presente trabajo puedan variar entre la lengua románica y la lengua eslava, aunque las normas de puntuación basadas en la sintaxis muestren diferencias entre las dos lenguas confrontadas, lo cierto es que la unificación del uso de la coma se halla en el nivel funcional, dado que tanto en español como en polaco todas las estructuras en función explicativa se separan mediante comas del resto del enunciado, mientras que las estructuras en función especificativa no admiten signo de puntuación alguno para integrarse por completo al enunciado del que forman parte.

\section{Bibliografía}

BAŃKO, M. (ed.) (2006), Polszczyzna na co dzień, Wydawnictwo Naukowe PWN, Warszawa.

MARKOWSKI, A., WICHROWSKA, W. (2009), Wielki stownik ortograficzny, Buchmann, Warszawa.

RAE y la ASALE = REAL ACADEMIA ESPAÑOLA Y ASOCIACIÓN DE ACADEMIAS DE LA LENGUA ESPAÑOLA (2010), Ortografía de la lengua española, Espasa Libros, Madrid.

Wielki słownik ortograficzny (2006), [on-line] http://so.pwn.pl/zasady. php?id=629769 -13.05 .2013 . 